\title{
Anionic sites in diabetic basement membranes and their possible role in diffusion barrier abnormalities in the BB-rat
}

\author{
S.Chakrabarti, N.Ma and A. A.F.Sima \\ Neuropathology Research Laboratories, Department of Pathology, University of Manitoba, Winnipeg, Manitoba, Canada
}

\begin{abstract}
Summary. Basement membrane anionic sites, thought to be responsible for charge selective permeability barriers, were investigated in retinal, endoneurial, and muscle capillary basement membranes and in Bruch's membrane of diabetic, and age- and sex-matched non-diabetic BB-rats using an ultrastructural quantitative histochemical technique. Six months of diabetes was associated with significant basement membrane thickening which was linearly related to a decrease in anionic site density suggesting a relative loss of proteoglycans. Calculation of anionic sites per unit length of basement membrane, reflecting their absolute number, revealed a significant loss in basement membrane, constituting part of normal blood-tissue barrier systems such as reti-
\end{abstract}

nal and endoneurial capillary basement membranes, and the basement membrane of the retinal pigment epithelium. The absolute number of anionic sites in normally permeable microvessels, such as those of muscle and choriocapillaries, was unaltered by diabetes. We conclude that this specific loss of anionic sites in basement membranes of tissues affected by chronic diabetic complications may in part be responsible for permeability abnormalities seen in these tissues.

Key words: Capillary basement membranes, Bruch's membrane, anionic sites, cuprolinic blue, BB-Wistar rat.
Diabetic microangiopathy is characterized by capillary basement membrane (BM) thickening and increased capillary permeability $[1,2]$. The generalized increase in capillary BM thickness also affects the glomerular BM and Bruch's membrane of the retina [1,3-5]. Increased capillary permeability to ${ }^{125} \mathrm{I}$-albumin has been described in tissues affected by chronic diabetic complications, such as peripheral nerve, kidney and the retina, whereas capillary permeability properties of skeletal muscle, heart and brain are usually unaffected by diabetes despite BM thickening [2]. This is also true for small molecular weight species such as ${ }^{14} \mathrm{C}$-mannitol, which shows an increased permeation in peripheral nerve but not in the brain of streptozotocin diabetic rats [6]. The exact mechanisms responsible for these abnormalities in diabetic microvessels are not known. However, it has been suggested that non-enzymatic glycosylation and subsequent formation of advanced glycosylated end products, through fine architectural changes in the BM structure, may impair the function of the size selective BM barrier. Loss of BM anionic sites on the other hand is believed to be responsible for alterations in the charge selective barrier [5]. BM proteoglycans, in particular heparan sulphate which is periodically distributed along the BM sur- faces, constitute the charge selective anionic barrier by virtue of electrostatic repulsion and steric hindrance $[5,7]$.

Hence, part of the impaired function of the BM barriers in diabetes may be the result of decreased synthesis and/or altered turnover of proteoglycans and BM thickening secondary to trapping of plasma proteins or by an increase in the synthesis or decrease in the removal of $\mathrm{BM}$ proteins [5, 7-9].

Proteoglycans can be visualized ultrastructurally with a high degree of specificity by using the cationic dye cuprolinic blue and the critical electrolyte concentration method [10-13]. Employing this technique we have previously demonstrated a significant loss of anionic sites in association with glomerular BM thickening in the diabetic BB-rat [14]. For comparison these data were included in the present communication, in which we have extended the previous study to include a variety of tissues from the diabetic BB-rat, demonstrating a generalized relative loss of anionic sites in diabetic BMs, whereas an absolute loss of anionic sites appeared to be characteristic of BMs which form part of diffusion barrier systems. 


\section{Materials and methods}

\section{Animals}

Six male diabetic BB-rats and six age- and sex-matched non-diabetic $\mathrm{BB}$ rats were obtained from Health and Welfare Canada, (Ottawa, Ontario, Canada) and examined in this study. The animals were maintained in air filtered metabolic cages with alternate $12 \mathrm{~h}$ light and dark cycles and with access to a commercial rat chow (Wayne Lab Blox, Chicago, Ill., USA) and water ad libitum. Diabetic animals were maintained on small daily doses $(0.5-3.0 \mathrm{U} / \mathrm{day})$ of protamine zinc insulin (Connaught-Novo Inc., Don Mills, Ontario, Canada) to prevent ketosis. They were monitored daily with respect to urine volume, sugar and ketones. Blood glucose levels, glycosylated haemoglobin levels and body weights were monitored regularly as previously described [3]. The rats were killed after six months of diabetes.

\section{Tissue collection}

The animals were killed after $4-6 \mathrm{~h}$ of light exposure. They were an aesthetized by intraperitoneal $\mathrm{Na}$-pentobarbital $(50 \mathrm{mg} / \mathrm{kg}$ of body weight). The following tissues were obtained from the left side: the posterior eyecup within $3 \mathrm{~mm}$ of the optic nerve head, the gastrocnemius muscle, the sciatic nerve, and the renal cortex. All tissues were processed simultaneously and were fixed by immersion in $2.5 \%$ gluteraldehyde in $0.02 \mathrm{~mol} / \mathrm{l}$ acetate-buffer ( $\mathrm{pH} 5.6$ ), containing $0.2 \%$ cuprolinic blue (British Drug House Ltd., Pole, UK) and $0.2 \mathrm{~mol} / \mathrm{l}$ magnesium chloride for adjustment of the critical electrolyte concentration [10-13]. Tissues were then processed and examined electronmicroscopically as previously described in detail [14]. The same tissues were obtained from the right side and fixed in the same fixative containing no cuprolinic blue. These tissues were processed in an identical fashion at the same time and served as negative controls.

\section{Quantitative techniques}

Electronmicrographs with a total magnification ranging from 30,000 to 44,000 times were used for the quantitative assessment of anionic sites. Ten randomly selected, transversely sectioned capillaries from each of the superficial (nerve fiber layer and ganglion cell layer) and the deep capillary bed (outer plexiform layer and inner nuclear layer) of the retina, and the gastrocnemius muscle were investigated. In each sciatic nerve a mean of $5.0 \pm 0.6( \pm$ SEM $)$ capillaries per nerve were examined. The randomization of the sampling was influenced by the presence of cross-sectioned capillaries which were judged as such when the ratio between the largest to the smallest diameters was less than 1.5. Ten random areas of Bruch's membrane from individual samples, each measuring approximately $10 \mu \mathrm{m}$ in length, were selected for examination. Attention was paid to the thickness of ultrathin sections, which measured approximately $65 \mathrm{~nm}$. The total number of staining products, representing anionic sites, were counted and expressed as number $/ \mu^{2}{ }^{2}$ of $\mathrm{BM}$ area and number/ $\mu \mathrm{m}$ of $\mathrm{BM}$ length. Hence, since the thickness of the sections was kept constant, the values reflect the number of anionic BM sites per volume. In the Bruch's membrane the number of anionic sites per unit length of the retinal pigment epithelium $\mathrm{BM}$ and the choriocapillary BM were examined separately. BM thickness and areas were measured with the aid of a Hewlett Packard 9874A digitizer interfaced with a Hewlett Packard 9875A computer (Hewlett Packard, Fort Collins, Co., USA) as previously described in detail [15]. In brief, the total capillary area was measured from which pericyte and endothelial cell profile areas, and the luminal area were subtracted to obtain the BM area. The BM length was obtained by measuring the lengths of the lines delineating the $\mathrm{BM}$ and dividing by 2 . The $\mathrm{BM}$ thickness was derived from BM area divided by BM length. The thickness of the Bruch's membrane was calculated by dividing the area by the length. All measurements were performed by an investigator (NM) unaware of the source of the samples.

\section{Statistical analysis}

The data are expressed as means \pm SEM and were analysed by Student's two tailed $t$-test and linear regression analysis by the least square method.

\section{Results}

Diabetic animals demonstrated, at termination of the experiment, hyperglycaemia $(22.3 \pm 1.3 \mathrm{vs} 6.1 \pm 0.9 \mathrm{mmol} / \mathrm{l}$, $p<0.001)$, elevated glycosylated haemoglobin $(11.2 \pm 0.5$ vs $5.2 \pm 0.4 \%, p<0.001)$ and decreased body weight $(409.7 \pm 23.7$ vs $539.0 \pm 21.6 \mathrm{~g}, p<0.01)$ compared to controls, as well as polyuria ( $>30 \mathrm{ml} / 24 \mathrm{~h}$ ) accompanied by glucosuria ( $>110.0 \mathrm{mmol} / \mathrm{l}$ ) and occasionally ketonuria. Control animals in contrast showed a $24 \mathrm{~h}$ urine output of $<5 \mathrm{ml}$ and no glucosuria or ketonuria.

BMs of the superficial and deep capillary beds of the retina, gastrocnemius muscle, and the sciatic nerve, as well as Bruch's membrane showed increased thicknesses in diabetic rats compared to non-diabetic control animals. In the retina both control and diabetic animals showed a thicker BM in the superficial capillary bed compared to that of the deep bed (Table 1). Tissue blocks fixed in the fixative containing cuprolinic blue demonstrated electron-dense filamentous staining products in capillary BMs and in Bruch's membrane corresponding to anionic sites (Fig. 1,2). When the staining products were cut on end they showed a dot-like appearance. In capillary BMs of the retina and the sciatic nerve, cuprolinic blue positive sites were distributed periodically along both the inner and outer surfaces of the BMs, whereas in muscular capillaries the staining product was concentrated close to the outer surface of the BM (Fig. 3). When the BM was split to encircle pericytes, an-

Table 1. Basement membrane (BM) thickness (nm) (mean + SEM)

\begin{tabular}{lllclll}
\hline & $\begin{array}{l}\text { Superficial retinal } \\
\text { capillary BM }\end{array}$ & $\begin{array}{l}\text { Deep retinal capillary } \\
\text { BM }\end{array}$ & Bruch's membrane & $\begin{array}{l}\text { Muscle capillary } \\
\text { BM }\end{array}$ & $\begin{array}{l}\text { Endoneurial capillary } \\
\text { BM }\end{array}$ & $\begin{array}{l}\text { Glomerular* } \\
\text { BM }\end{array}$ \\
\hline Diabetic & $211.8 \pm 8.1^{\mathrm{a}}$ & $188.2 \pm 4.9^{\mathrm{a}}$ & $1092.4 \pm 144.9^{\mathrm{b}}$ & $155.6 \pm 4.9^{\mathrm{a}}$ & $206.4 \pm 10.3^{\mathrm{a}}$ & $431.0 \pm 20.2^{\mathrm{c}}$ \\
Control & $161.9 \pm 3.7$ & $142.7 \pm 3.3$ & $697.8 \pm 38.5$ & $125.0 \pm 3.2$ & $142.8 \pm 4.5$ & $326.0 \pm 20.0$ \\
\hline
\end{tabular}

${ }^{\mathrm{a}} p<0.001,{ }^{\mathrm{b}} p<0.005$ and $^{\mathrm{c}} p<0.01$ compared to controls by Student's $t$-test

* data previously published [14] 


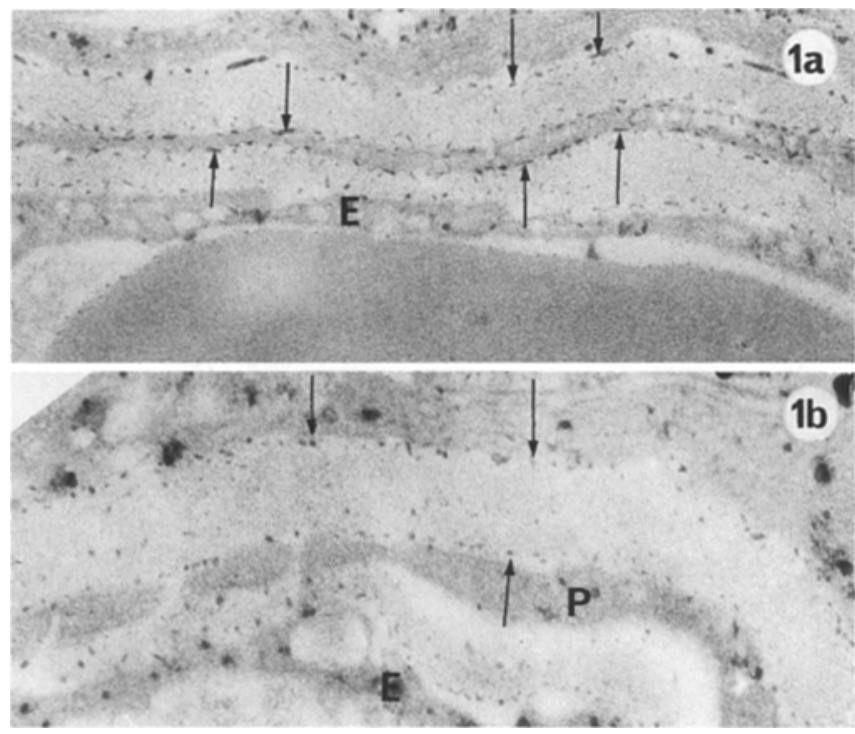

Fig. 1a, b. Electronmicrographs of superficial retinal capillary basement membranes from (a) a non-diabetic rat and (b) a diabetic rat following exposure to the cationic dye cuprolinic blue. Note a thicker basement membrane and reduced number of anionic sites (some of which are shown with arrows) in (b) compared to (a). Magnification 44,144 times for both micrographs. $\mathbf{P}=$ Pericyte,$E=$ Endothelial cell

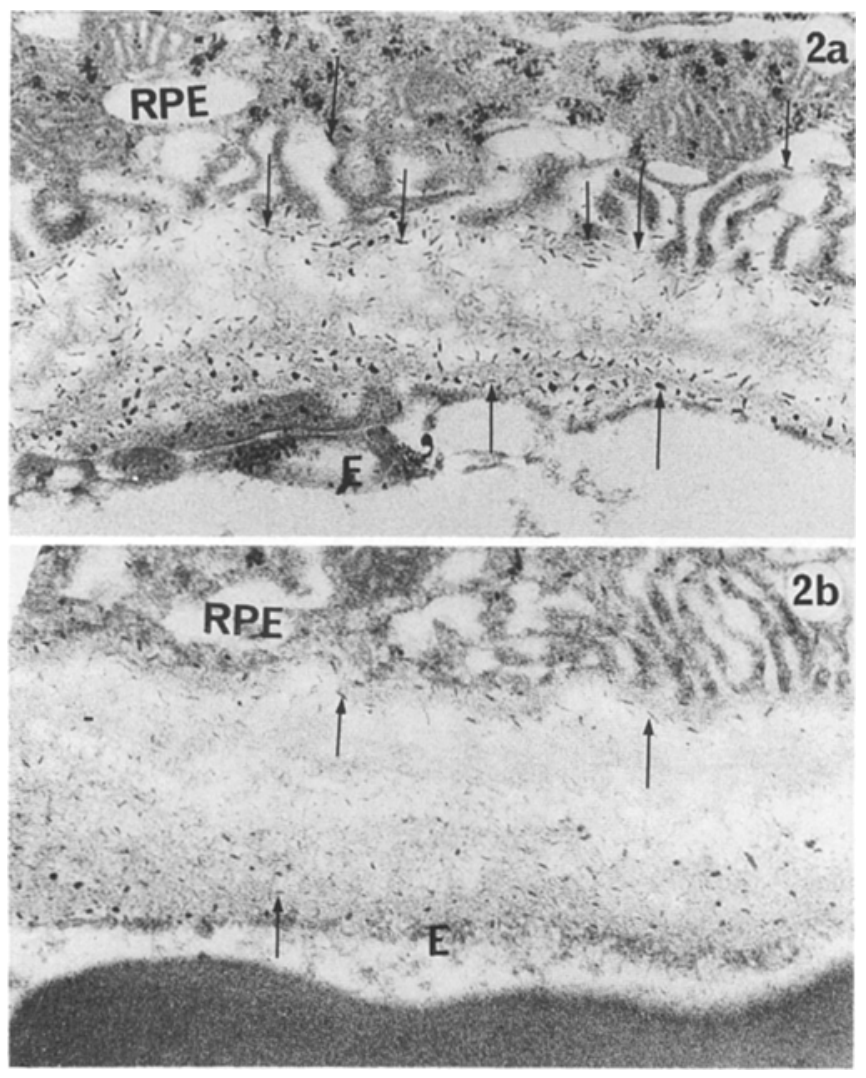

Fig. 2a,b. Electronmicrographs of Bruch's membrane from (a) a non-diabetic rat and (b) a diabetic rat following incubation with the cationic dye cuprolinic blue. Note a thicker Bruch's membrane and reduced number of anionic sites (some of which are shown with arrows) in (b) compared to (a). Magnification 35,190 times for both micrographs. $\mathrm{RPE}=$ Retinal pigment epithelium, $\mathrm{E}=$ Endothelial cell
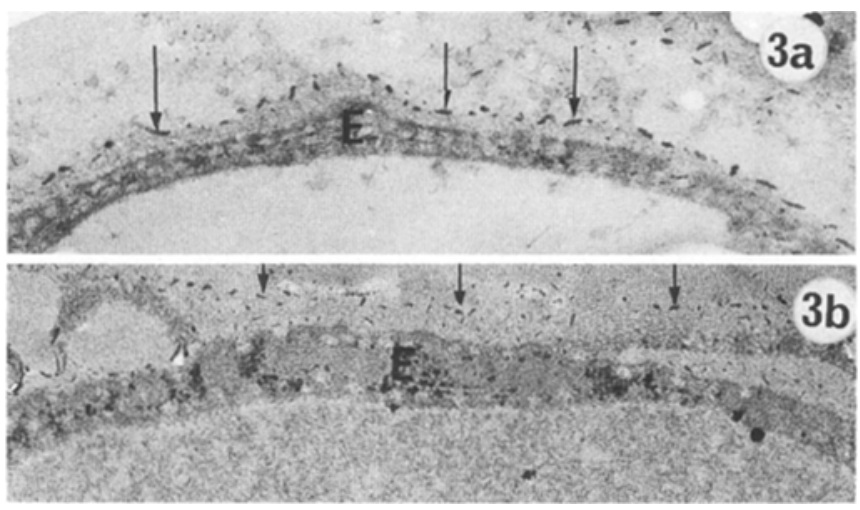

Fig. 3a, b. Electronmicrographs of muscle capillary BMs from (a) a non-diabetic rat and (b) a diabetic rat following exposure to the cationic dye cuprolinic blue. Note a thicker basement membrane and reduced number of anionic site (some of which are shown with arrows) in (b) compared to (a). The anionic sites are distributed close to the outer surface of the basement membrane. Magnification 36,450 times for both micrographs. $\mathrm{E}=$ Endothelial cell

ionic sites were seen in both the inner and the outer BMs. Electron-dense staining products were distributed randomly in the core of BMs. No apparent difference in anionic site density was observed between the inner and outer surfaces of BMs, except for BMs encircling muscular capillaries, nor were any differences noted in anionic site density between the superficial and deep capillary beds of the retina. In Bruch's membrane anionic sites were found in the retinal pigment epithelium BM, the choriocapillary BM and in association with collagen fibrils (Fig.2). No staining products were seen in tissues fixed in solutions containing no cuprolinic blue.

Quantitation of staining sites revealed in diabetic rats a significant reduction in the density of anionic sites in BMs of the superficial and deep capillary beds of the retina, muscle and sciatic nerve capillaries, as well as in Bruch's membrane (Table 2). However, when the number of anionic sites was calculated per unit length of BM, a significant reduction was observed only in retinal, and endoneurial capillaries, and in the retinal pigment epithelium BM of diabetic rats, but not in muscle capillaries of choriocapillaries (Table 3 ). In both diabetic and control rats the number of anionic sites per unit length of the choriocapillary BM was significantly higher than that of the retinal pigment epithelium BM. Cuprolinic blue positive sites were also seen along the basal plasmalemmal infoldings of the retinal pigment epithelium. Although not quantified, they appeared to be reduced in number in diabetic rats.

We have previously demonstrated a significant loss in anionic site density in glomerular BM in diabetic rats [14]. Calculation of the absolute number of anionic sites per unit length of glomerular BM showed a significant reduction in diabetic animals compared to age-matched control rats (Table 3 ).

Linear regression analyses of BM thickness with the density of anionic sites as the independent variable showed a significant negative relationship in all BMs suggesting that $\mathrm{BM}$ thickening is associated with a relative loss of anionic sites (Table 4). However, when the number 
Table 2. Density of anionic sites (\#/unit area) (mean + SEM)

\begin{tabular}{lccccc}
\hline & $\begin{array}{l}\text { Superficial retinal } \\
\text { capillary BM }\end{array}$ & $\begin{array}{l}\text { Deep retinal capillary } \\
\text { BM }\end{array}$ & Bruch's membrane & Muscle capillary BM & $\begin{array}{l}\text { Endoneurial capillary } \\
\text { BM }\end{array}$ \\
\hline Diabetic & $68.3 \pm 6.9^{\mathrm{a}}$ & $61.0 \pm 7.4^{\mathrm{a}}$ & $75.8 \pm 2.3^{\mathrm{b}}$ & $101.5 \pm 6.3^{\mathrm{b}}$ & $56.7 \pm 2.6^{\mathrm{a}}$ \\
Control & $112.1 \pm 6.6$ & $118.6 \pm 5.0$ & $95.4 \pm 6.3$ & $135.0 \pm 3.7$ & $129.8 \pm 6.9^{\mathrm{a}}$ \\
\hline
\end{tabular}

${ }^{\mathrm{a}} p<0.001,{ }^{\mathrm{b}} p<0.002$ compared to controls by Student's $t$-test; $\mathrm{BM}=$ basement membrane

* data previously published [14]

Table 3. Absolute number of anionic sites ( \#/unit length) (mean + SEM)

\begin{tabular}{|c|c|c|c|c|c|c|c|}
\hline & $\begin{array}{l}\text { Superficial retinal } \\
\text { capillary BM }\end{array}$ & $\begin{array}{l}\text { Deep retinal } \\
\text { capillary } \mathrm{BM}\end{array}$ & $\begin{array}{l}\text { Retinal pigment } \\
\text { epithelium BM }\end{array}$ & $\begin{array}{l}\text { Choriocapillary } \\
\text { BM }\end{array}$ & $\begin{array}{l}\text { Muscle capillary } \\
\text { BM }\end{array}$ & $\begin{array}{l}\text { Endoneurial } \\
\text { capillary BM }\end{array}$ & $\begin{array}{l}\text { Glomerular } \\
\text { BM }\end{array}$ \\
\hline Diabetic & $13.6 \pm 1.0^{c}$ & $11.3 \pm 1.0^{\mathrm{a}}$ & $18.5 \pm 1.6^{\mathrm{d}}$ & $25.4 \pm 1.3$ & $15.5 \pm 1.0$ & $11.3 \pm 0.7^{b}$ & $46.0 \pm 0.9^{\mathrm{d}}$ \\
\hline Control & $17.5 \pm 0.9$ & $16.5 \pm 0.7$ & $22.9 \pm 1.0$ & $28.2 \pm 0.6$ & $16.4 \pm 0.4$ & $16.1 \pm 1.3$ & $56.3 \pm 3.9$ \\
\hline
\end{tabular}

${ }^{\mathrm{a}} p<0.002,{ }^{\mathrm{b}} p<0.01,{ }^{\mathrm{c}} p<0.02$ and ${ }^{\mathrm{d}} p<0.05$ compared to controls by Student's $t$-test

Table 4. Regression analysis of basement membrane (BM) thickness

\begin{tabular}{llllll}
\hline & $\begin{array}{l}\text { Superficial retinal } \\
\text { capillary BM }\end{array}$ & $\begin{array}{l}\text { Deep retinal capillary } \\
\mathrm{BM}\end{array}$ & $\begin{array}{l}\text { Endoneurial capillary } \\
\mathrm{BM}\end{array}$ & Muscle capillary BM & Bruch's membrane \\
\hline $\begin{array}{l}\text { Independent } \\
\text { variable }\end{array}$ & & & & & \\
$\begin{array}{l}\text { Anionic site } \\
\text { density }\end{array}$ & $\begin{array}{l}r=-0.929(p<0.001) \\
\text { Absolute }\end{array}$ & $\begin{array}{l}r=-0.89(p<0.001) \\
\mathrm{F}=37.15\end{array}$ & $\begin{array}{l}r=-0.8(p<0.001) \\
\mathrm{F}=24.5\end{array}$ & $\begin{array}{l}r=-0.8(p<0.001) \\
\mathrm{F}=24.8\end{array}$ & $r=-0.8(p<0.001)$ \\
$\begin{array}{l}\text { number of } \\
\text { anionic sites }\end{array}$ & $\begin{array}{l}r=-0.79(p<0.001) \\
\mathrm{F}=16.85\end{array}$ & $\begin{array}{l}r=-0.71(p<0.005) \\
\mathrm{F}=10.24\end{array}$ & $\begin{array}{l}r=-0.56(p<0.05) \\
\mathrm{F}=4.46\end{array}$ & $\begin{array}{r}r=-0.23 \\
\mathrm{~F}=0.54\end{array}$ \\
\hline
\end{tabular}

of anionic sites per unit length of BM was used as the independent variable, significant negative relationships were demonstrated only in the retinal and endoneurial capillaries indicating that in these microvessels BM thickening is also associated with an absolute loss of anionic sites (Table 4). These calculations were not performed on the Bruch's membrane, since the delineation of the two BMs is structurally ill defined.

\section{Discussion}

The mechanisms responsible for increased vascular permeability in the target organs of diabetic complications are not known. Several possibilities have been suggested, such as: (1) increased transendothelial pinocytotic transfer [16] (2) increased interendothelial transport facilitated by loss of endothelial cell tight junctions $[16,17]$ and (3) altered function of the size and charge selective barriers of the $\mathrm{BM}[5]$.

Periodic distribution of proteoglycans, demonstrated as anionic sites is believed to be the molecular substrate for the charge selective BM barrier [5,7]. In the present study, we demonstrated a decrease in the density of BM anionic sites, which correlated with the characteristic BM thickening in diabetes. The decreased density of anionic sites affected capillaries which normally constitute a blood-tissue barrier, as well as those which are normally permeable such as, muscle capillaries and choriocapillaries. These findings are in keeping with our previous data demonstrating a decreased density of anionic sites in the thickened diabetic glomerular BM [14] and indicate a dilution effect on anionic sites with BM thickening, suggesting that BM thickening is either an isolated phenomenon occurring in the presence of normal proteoglycan synthesis and/or turnover, or that BM thickening occurs simultaneously with a propositional decrease in proteoglycans. In order to examine these two possibilities, anionic sites were calculated per unit length of BM and compared in equally thick sections, thus reflecting the absolute number of anionic sites.

In the present study the retinal pigment epithelium BM of the Bruch's membrane showed a significant absolute reduction in the number of anionic sites, whereas they were not significantly reduced in the choriocapillary BM. In a previous report using a different histochemical technique, both these membranes showed significant reductions of anionic sites in diabetes [4]. Loss of anionic sites in the diabetic retinal pigment epithelium $\mathrm{BM}$ may be one mechanism responsible for the increased permeability across the Bruch's membrane $[4,18]$. This abnormality may be secondary to a defect in proteoglycan - extracellular matrix interaction [19], or to a defect in proteoglycan synthesis and/or delivery by altered plasmalemmal infoldings, as previously demonstrated in the BB-rat $[4,18]$. The latter notion is supported by the decreased presence of cuprolinic blue staining products in the plasmalemmal infoldings of the retinal pigment epithelium believed to represent membrane intercalated heparan sulphate proteoglycans, [20]. 
$\mathrm{BM}$ thickening in diabetes is thought to be, at least in part, a consequence of increased production of BM proteins such as, collagen IV and laminin [5, 7, 21-23]. In the glomerular BM this enhanced synthesis of structural proteins may be coupled with a decreased de novo synthesis of proteoglycans [5, 7-9]. These findings imply that the proteoglycan defect in the diabetic glomerular BM is not only caused by the dilution defect secondary to BM thickening but is also contributed to by an absolute loss of proteoglycans.

In order to examine whether an absolute loss of anionic sites, suggesting impaired proteoglycan synthesis, is unique for the glomerular BM, or a universal phenomenon in diabetes, we assessed the absolute number of anionic sites in various BMs. Calculations of the number of cuprolinic blue staining sites per unit length of BM revealed an absolute loss of anionic sites in the retinal and endoneurial capillary BMs, the glomerular BM and in the $\mathrm{BM}$ of retinal pigment epithelium cells, whereas the BM of choriocapillaries and muscle capillaries revealed no absolute loss of anionic sites. These data, therefore, suggest that as in the glomerular BM, a decreased synthesis of proteoglycans occurs in the BMs which form part of diffusion barrier systems in tissues affected by diabetic complications. This notion is further supported by the fact that the absolute decrease in anionic sites correlated with $\mathrm{BM}$ thickening in the retinal and endoneurial capillaries but not in BMs of normally permeable capillary systems.

Since it is believed that $\mathrm{BM}$ anionic sites constitute an integral part of diffusion barrier system [5,7], their selective loss in tissues affected by diabetic complications, may provide one mechanism to explain the abnormal permeability of these tissues in diabetes [2,24]. Williamson et al. have previously demonstrated that the permeability abnormalities occuring in diabetic rats are reversible following treatment with an aldose reductase inhibitor as well as by castration [2]. Beyer-Mears et al. were able to demonstrate a diminished urinary protein excretion in diabetic BB-rats following three months treatment with an aldose reductase inhibitor [24]. Furthermore, we and others have demonstrated that the characteristic BM thickening in diabetes can be prevented by aldose reductase inhibition $[3,25]$. This constellation of findings suggest that BM thickening and impaired permeability properties may in part occur as a consequence of an activated polyol pathway. The immunocytochemical localization of aldose reductase in retinal pigment epithelium, microvascular cells of the retina, and the endoneurium, and in podocytes of the glomerulus, would be consistent with the notion that an increased polyol pathway activity may be a factor contributing to decreased proteoglycan synthesis by these cells $[18,26-28]$. Confirmation of this supposition though has to await the demonstration of a normalization of anionic sites following aldose reductase inhibitor treatment, and clarification of the exact mechanism(s) by which an augmented polyol pathway activity selectively affects proteoglycan synthesis.

Acknowledgements. The present study was supported in part by grants from the Canadian Diabetes Association and the Medical Research Council of Canada. Dr. Chakrabarti is the recipient of a postdoctoral fellowship from Diabetes Canada.

\section{References}

1. Williamson JR, Tilton RG, Chang K, Kilo C (1988) Basement membrane abnormalities in diabetes mellitus: relationship to clinical microangiopathy. Diab Metabol Review 4: 339-370

2. Williamson JR, Chang K, Tilton RG, Prater C, Jeffrey JR, Weigel C, Sherman WR, Eades DM, Kilo C (1987) Increased vascular permeability in spontaneously diabetic $\mathrm{BB} / \mathrm{W}$ rats and in rats with mild versus severe streptozotocin-induced diabetes: prevention by aldose reductase inhibition and castration. Diabetes 36: 813-821

3. Chakrabarti S, Sima AAF (1989) Effect of aldose reductase inhibition and insulin treatment on retinal capillary basement membrane thickening in BB rats. Diabetes 38:1181-1186

4. Caldwell RB, Slapnick SM, McLaughlin BJ (1986) Decreased anionic sites in Bruch's membrane of spontaneous and drug-induced diabetes. Invest Ophthalmol Vis Sci 27: 1691-1697

5. Schleicher E, Nerlich A, Gerbitz K-D (1988) Pathobiochemical aspects of diabetic nephropathy. Klin Wochenschr 66: 873-882

6. Rechthand E, Smith QR, Latker CH, Rapaport SI (1987) Altered blood-nerve barrier permeability to small molecules in experimental diabetes mellitus. J Neuropath Exp Neurol 46: 302-314

7. Rohrbach DH, Martin GR (1982) Structure of basement membrane in normal and diabetic tissue. Ann New York Acad Sci 401: 203-209

8. Kanwar YS, Rosenzweig LJ, Linker A, Jakubowski ML (1983) Decreased de novo synthesis of glomerular proteoglycans in diabetes: biochemical and autoradiographic evidence. Proc Natl Acad Sci 80: 2272-2275

9. Parthasarathy N, Spiro RG (1982) Effect of diabetes on the glycosaminoglycan component of human glomerular basement membrane. Diabetes 31:738-741

10. Scott JE (1987) Proteoglycan histochemistry - a valuable tool for connective tissue biochemists. Coll Rel Res 5: 541-575

11. Van Kuppevelt THMSM, Rutten TLM, Kuyper CMA (1987) Ultrastructural localization of proteoglycans in tissue using cuprolinic blue according to the critical electrolyte concentration method: comparison with biochemical data from the literature. Histochem J 19: 520-526

12. Van Kuppevelt THMSM, Domen JGW, Cremers FPM, Kuyper CMA (1984) Staining of proteoglycans in mouse lung alveoli. I. Ultrastructural localization of anionic sites. Histochemical J 16 : 657-669

13. Van Kuppevelt THMSM, Cremers FPM, Domen JGW, Kuyper CMA (1984) Staining of proteoglycans in mouse lung alveoli. II. Characterization of the cuprolinic blue-positive, anionic sites. Histochemical J 16: 671-686

14. Chakrabarti S, Ma N, Sima AAF (1989) Reduced number of anionic sites is associated with glomerular basement membrane thickening in the diabetic BB-rat. Diabetologia 32: 826-828

15. McEwen TAJ, Chakrabarti S, Sima AAF (1987) A rapid reproducible method for the determination of basement membrane thickness in biological structure. Comp Biol Med 17: 193197

16. Ishibashi T, Tanaka K, Taniguichi Y (1980) Disruption of bloodretinal barrier in experimental diabetic rats: an electron microscopic study. Exp Eye Res 30: 401-410

17. Sima AAF, Nathaniel V, McEwen TAJ, Bril V, Greene DA (1988) Vascular pathology in diabetic nerve and lack of effect following ARI treatment. Diabetes 37 [Suppl]: 45A

18. Chakrabarti S, Prashar A, Sima AAF (1990) Augmented polyol pathway activity and retinal pigment epithelium permeability in the diabetic BB-rat. Diab Res Clin Prac 8: 1-12

19. Klein DJ, Oegema TR Jr, Brown DM (1989) Release of glomerular heparan $-{ }^{35} \mathrm{SO}_{4}$ proteoglycan by heparin from glomeruli of streptozocin-induced diabetic rats. Diabetes 38: 130-139

20. Stow JL, Sanda H, Farquhar GM (1986) Basement membrane heparan sulphate proteoglycans are concentrated in the laminae rarae and podocytes of the rat renal glomerulus. Proc Natl Acad Sci USA $82: 3296-3300$ 
21. Li W, Shen S, Khatami M, Rockey JH (1984) Stimulation of retinal capillary pericyte protein and collagen synthesis in culture by high glucose concentration. Diabetes 33: 785-789

22. King GL, Berman A, Ledbetter S (1988) Regulation of type IV collagen mRNA in retinal capillary endothelial cells and pericytes by glucose levels and aldose inhibitor. Invest Ophthalmol Vis Sci 29 [Suppl]: 181

23. Polsum R, Kurkinen M, Prockop DJ, Boot-Hanford RP (1988) Increased steady state levels of laminin $B_{1}$ mRNA in kidneys of long term streptozotocin diabetic rats: no effect of an aldose reductase inhibitor. J Biol Chem 263: 10072-10076

24. Beyer-Mears A, Murray FT, Cruz E, Rountree J (1990) Ponalrestat, diminution of proteinuria in the BB-rat. Diabetes 39 [Suppl]: 94A (Abstract)

25. Chandler ML, Shannon WA, DeSantis L (1984) Prevention of retinal capillary basement membrane thickening in diabetic rats by aldose reductase inhibitor. Invest Ophthalmol Vis Sci 25 [Suppl]: 159

26. Chakrabarti S, Sima AAF, Nakajima T, Yagihashi S, Greene DA (1987) Aldose reductase in the BB-rat: isolation, immunological identification and localization in the retina and peripheral nerve. Diabetologia 30: 244-251

27. Ludvigson MA, Sorenson RL (1980) Immunocytochemical localization of aldose reductase. II. Rat eye and kidney. Diabetes 29: 450-459

28. Terubayashi H, Sato S, Nishimura C, Kador PF, Kinoshita JH (1989) Localization of aldose reductase and aldehyde reductase in the kidney. Kindey Int 36: 843-851

Received: 30 March 1990

and in revised form: 3 December 1990

Prof. A. A.F. Sima

Michigan Diabetes Research and Training Center

The University of Michigan

1331 East Ann Strcet Bldg.

Ann Arbor, MI 48109-0580

USA 